\title{
High-Speed Compulsator Stator Thermal Management
}

\author{
Hsing P. LIU and Jonathan J. HAHNE
}

\begin{abstract}
The compulsator stator armature winding includes multiple conductor layers. Each conductor layer is made of insulation wraps and transposed aluminum litz wire bundles with epoxy potting compound between the wires and the wire bundles. For a typical pulse-duty application, based on a room-temperature electrical loss calculation, the temperature rise in the aluminum winding is approximately $30^{\circ} \mathrm{C}$ per shot. Adequate active cooling must be provided such that the stator insulation can survive thermally under a certain pulse repetition rate. The thermal management is quite challenging since the heat loss in the litz wires needs to be conducted through multiple insulations before reaching the coolant passages. As a result of the low equivalent thermal conductivities of the stator winding in the transverse direction, without compromising the overall structural integrity of the winding, the coolant passages have to be allocated as close as possible to the heat sources. For a given electric gun firing mission, four different cooling configurations have been investigated and analyzed by using water ethylene glycol mixture as an active liquid coolant. In this paper, thermal analysis cooling parameters, transient stator winding temperature distributions, hot-spot temperature histories are presented, discussed, and compared.
\end{abstract}

\section{INTRODUCTION}

$\mathrm{R}$ EPETITIVELY-FIRED electromagnetic railguns have been a subject of research interest in the past due to their capability of accelerating projectiles to hypervelocities in combat applications. A compact power supply plays an important role in meeting the mobile requirements of such applications. For high energy projectile launching, significant amount of heat losses are generated in the power supplies. Active cooling of the energy storage systems are typically required to prevent the system components from overheating during repetitive railgun firing. In this paper, thermal management of stator armature coils of a compulsator [1,2] is presented and discussed.

For a typical railgun shot, a temperature rise of $30^{\circ} \mathrm{C}$ is calculated in the aluminum stator armature winding of a compulsator, which is currently designed by The University of Texas at Austin Center for Electromechanics (UT-CEM).

Manuscript received January 4, 2002. A portion of this research was carried out under the Electric Gun Program sponsored by the U.S. Army Research Laboratory through Lockheed-Martin Missile and Fire Control under contract number 4300050944. Authors are affiliated with The University of Texas at Austin Center for Electromechanics, Austin, Texas 78758, (512) 471-4496, fax (512) 471-0781.
Adequate active cooling must be provided such that the stator insulation can survive thermally under a certain pulse repetition rate. The heat loss generated in the coil winding, which is made of aluminum litz wires, needs to be conducted through multiple insulations before reaching the coolant passages. As a result of the low equivalent thermal conductivities of the stator winding in the transverse direction, without compromising the overall structural integrity of the winding, the coolant passages have to be allocated as close as possible to the heat sources.

\section{Stator ARmature Winding Cooling Design}

Typically, the thermal limitation of an electrical machine is the electrical insulation. To ensure a thermal margin and a certain service life from the insulation, the cooling system is designed so that the maximum stator coil transient temperature does not exceed $150^{\circ} \mathrm{C}$ (suitable for Class $\mathrm{F}$ insulation), but the insulation materials actually used will be Class $\mathrm{H}$ (capable of continuous operation at $\left.180^{\circ} \mathrm{C}\right)$.

Four stator cooling configurations (Figs. 1 to 4 ) have been designed and analyzed:

- A - coolant tubes replace three transposed conductor wire bundles in each coil

- B - two cooling layers (six small coolant tubes per layer) are inserted into each coil

- C - coolant tubes replace four transposed conductor wire bundles in each coil

- $\quad \mathrm{D}$ - ten miniature coolant tubes are alternately allocated in each coil

For all cooling configurations, the coolant tubes, which are made of copper, are transposed along with conductor wire bundles that are $4 \mathrm{~m}$ long per coil. An aqueous mixture of $60 \%$ water and $40 \%$ ethylene glycol is chosen as the coolant. In the stator transient thermal analyses described later, both the ambient temperature and stator's initial temperature were assumed to be $49^{\circ} \mathrm{C}\left(120^{\circ} \mathrm{F}\right)$.

In configuration $\mathrm{A}$, three transposed conductor wire bundles within each coil are replaced by coolant tubes. Due to the loss of three current-carrying conductor wire bundles, more heat loss will be generated, as compared to the heat loss if all 22 conductor wire bundles are utilized to carry current. The calculated heat loss introduces a temperature rise of $44.7^{\circ} \mathrm{C}$ per shot in the aluminum litz wires. 
In configuration $\mathrm{B}$, each stator coil has two cooling layers and each cooling layer has six distributed small coolant tubes. Since the coolant tubes are above and beneath the conductor wire bundles, all 22 litz wire bundles in each coil can be used entirely to carry current. The temperature rise in the conductor wires per shot is $33.3^{\circ} \mathrm{C}$.

Configuration $\mathrm{C}$, which is similar to configuration A except four conductor wire bundles within each stator coil being replaced by coolant tubes, was also analyzed. The temperature rise in the conductor wires per shot is $49.7^{\circ} \mathrm{C}$.

In configuration $\mathrm{D}$, there are seven aluminum litz wires in each wire bundle and 22 wire bundles in each stator coil. Ten wire bundles within each coil are selected to replace the ten central conductor wires by ten coolant tubes. The outer diameters of the litz wires (16 AWG heavy aluminum magnet wires) and the copper coolant tubes are identical. The outer and inner diameters of the coolant tubes are 0.054 in. and 0.034 in., respectively. After reducing the currentcarrying area occupied by the ten miniature coolant tubes, the overall conductor wire packing factor in the entire 22 wire bundles of the configuration $\mathrm{D}$ is approximately $64.5 \%$. The temperature rise in the conductor wires per shot is $30.4^{\circ} \mathrm{C}$.

\section{StATOR ARMATURE Winding COOLING ANALYSIS}

Within each conductor bundle, the heat deposited in the aluminum wires can be diffused quickly into the surrounding insulations. It is estimated that a thorough thermal diffusion within a conductor bundle, which includes $63 \%$ aluminum wires and $37 \%$ insulations, can be achieved in 1 s. Two-dimensional planar finite element thermal models have been constructed to analyze transient thermal responses of the stator coils during a railgun firing mission. Stator armature coil heat loss will increase as coil temperatures increase from shot to shot. The transient thermal analysis for each cooling configuration was based on a constant heat loss per shot calculated at $49^{\circ} \mathrm{C}$ for the entire firing mission, and therefore under-predicted the armature coil temperatures somewhat. A constant coolant inlet temperature of $55^{\circ} \mathrm{C}\left(131^{\circ} \mathrm{F}\right)$ was assumed in the analyses to allow for a temperature differential of $6^{\circ} \mathrm{C}$ $\left(11^{\circ} \mathrm{F}\right)$ between the exit coolant of an external heat exchanger and the ambient air.

For simplicity and computational considerations, the small litz wires were not modeled individually in the cooling configurations $\mathrm{A}, \mathrm{B}$, and C; instead, both the wires and their surrounding insulations within each conductor bundle were treated as a monolithic material with calculated smeared thermal properties [3]. In the transient finite element thermal analyses for the cooling configurations A, $\mathrm{B}$, and $\mathrm{C}$, the heat losses were considered as uniform volumetric heat fluxes in all wire bundles which have combined aluminum and insulation smeared properties. Uniform heat deposition in $0.162 \mathrm{in}$. litz wire bundles was assumed to be achieved in $0.1 \mathrm{~s}$ during transient thermal analyses. However, for cooling configuration $\mathrm{D}$, since there are only seven magnet wires in each bundle and the wire size is relatively large, it may not be accurate to use the smeared thermal properties in the thermal modeling. In this particular configuration, we modeled all material individually, without using smeared properties for wire bundles. Materials modeled include copper tubes, wire insulation coating, epoxy potting compound between wires and wire bundles, insulation wraps, and G-10 support. Fig. 5 shows the planar finite element thermal model meshes. Fig. 6 shows the local details of the model meshes of the cooling configuration D.

Referring to Fig. 5, the left and right model exterior boundaries are adiabatic due to stator coil symmetries. The top exterior boundaries, which are in direct contact with the stator housing, were assumed to be adiabatic to ignore heat dissipation through stator housing. The bottom exterior boundaries, which are the stator inner surfaces, will be subjected to air-gap windage heating. High-speed windage loss calculations and high-speed heat transfer in rotating flows are very complicated. The possible air-gap air frictional heating to the stator inner surfaces was ignored in the stator thermal analyses presented in this paper, in which only the transient electrical losses were included. To reduce the thermal impact of the windage heating on the stator inner composite bore liner, a low pressure air will be maintained in the rotor/stator air gap.

For all four stator cooling configurations, cooling conditions and thermal analysis inputs are summarized in Tables 1 and 2. The coolant flow rates shown in Table 1 are for the entire 16 stator armature coils. For the cooling configuration $\mathrm{D}$, since the coolant tubes are very small, the coolant pressure drop is relatively significant compared to those of the other three cooling configurations. To reduce the coolant pressure drop and still maintain a turbulent flow cooling in the configuration D, a low flow rate of $8 \mathrm{gpm}$ was chosen,

Detailed transient thermal analyses for a given railgun firing mission have been performed. Figs. 7 through 10 show the stator temperature distributions immediately after the last shot. Fig. 11 shows the transient maximum stator coil temperatures. As shown in Figs. 7 through 10, the predicted maximum stator coil temperatures are $155.7^{\circ} \mathrm{C}$ for configuration $\mathrm{A}, 97.9^{\circ} \mathrm{C}$ for configuration $\mathrm{B}, 138.3^{\circ} \mathrm{C}$ for configuration $\mathrm{C}$, and $98^{\circ} \mathrm{C}$ for configuration $\mathrm{D}$.

\section{CONCLUSIONS}

For a compulsator energy storage system that is used to power multiple railgun projectile launching, four stator armature coil cooling designs have been proposed, analyzed, and compared. Under the described thermal analysis conditions, the following conclusions can be made:

- Cooling configuration A does not meet the cooling design goal since the transient maximum coil 
temperature of $155.7^{\circ} \mathrm{C}$ exceeds the maximum allowable design insulation temperature of $150^{\circ} \mathrm{C}$.

- Cooling configuration B looks good thermally; however, structural integrity during compulsator discharges and excessive coolant tube connections need to be investigated.

- Cooling configuration $\mathrm{C}$ appears to be on the borderline of the insulation thermal limit.

- Cooling configuration D can satisfy the cooling design goal by providing relatively high coolant pressure and having excessive miniature coolant tube connections.

To further refine the decoupled stator thermal analysis, the temperature dependent stator coil heat loss from shot to shot ought to be considered. Transient coupled rotor/stator thermal analysis, which includes windage loss and highspeed rotational flow heat transfer in the air gap, is worthwhile to be pursued, at the expense of complicated modeling and excessive computation effort.

\section{REFERENCES}

[1] M. L. Spann, S. B. Pratap, M. D. Werst, A. W. Walls, and W. G. Fulcher, "Compulsator Research at The University of Texas at Austin - An Overview," IEEE Transactions on Magnetics, vol. 25, no. 1, pp. 529-537, January 1989.

[2] S. B. Pratap, K. T. Hsieh, M. D. Driga, and W. F. Weldon, "Advanced Compulsators for Railguns," IEEE Transactions on Magnetics, vol. 25, no. 1, pp. 454-459, January 1989.

[3] W. M. Rohsenow, J. P. Hartnett, and E. N. Ganic, Handbook of Heat Transfer Fundamentals, Second ed., McGraw-Hill, New York, 1985. 
TABLE 1

SUMMARY OF STATOR COOLING CONDITIONS

\begin{tabular}{ccccccc}
\hline \hline $\begin{array}{c}\text { Configu- } \\
\text { ration }\end{array}$ & $\begin{array}{c}\text { Total } \\
\text { Flow } \\
\text { Rate } \\
(\mathrm{gpm})\end{array}$ & $\begin{array}{c}\text { Total } \\
\text { \# of } \\
\text { Coolant } \\
\text { Tubes }\end{array}$ & $\begin{array}{c}\text { Coolant } \\
\text { Inlet } \\
\text { Temp } \\
\left({ }^{\circ} \mathrm{C}\right)\end{array}$ & $\begin{array}{c}\text { Coolant } \\
\text { Exit } \\
\text { Temp } \\
\left({ }^{\circ} \mathrm{C}\right)\end{array}$ & $\begin{array}{c}\text { Average } \\
\text { Coolant } \\
\text { Velocity } \\
(\mathrm{m} / \mathrm{s})\end{array}$ & $\begin{array}{c}\text { Average } \\
\text { Pressure } \\
\text { Drop }^{*} \\
(\mathrm{psi})\end{array}$ \\
\hline A & 15 & 48 & 55 & 65.1 & 3.9 & 59 \\
B & 16 & 192 & 55 & 63.2 & 3.1 & 80.2 \\
C & 15 & 64 & 55 & 65.6 & 2.9 & 36 \\
D & 8 & 160 & 55 & 70.6 & 5.4 & 413 \\
\hline \hline
\end{tabular}

* Pressure drop values listed in table are for $4 \mathrm{~m}$ coolant tubes only; other hydraulic losses (i.e., manifolds, entrance, and exit losses) are not included

TABLE 2

SUMMARY OF STATOR COOLING ANALYSIS INPUTS

\begin{tabular}{ccccc}
\hline \hline $\begin{array}{c}\text { Configu- } \\
\text { ration }\end{array}$ & $\begin{array}{c}\text { Temperature } \\
\text { of Machine } \\
\left({ }^{\circ} \mathrm{C}\right)\end{array}$ & $\begin{array}{c}\text { Average } \\
\text { Coolant } \\
\text { Temperature } \\
\left({ }^{\circ} \mathrm{C}\right)\end{array}$ & $\begin{array}{c}\text { Average } \\
\text { Coolant } \\
\text { Reynolds } \\
\text { Number }\end{array}$ & $\begin{array}{c}\text { Average } \\
\text { Heat Transfer } \\
\text { Coefficient } \\
\left(\mathrm{W} / \mathrm{m}^{2} / \mathrm{K}\right)\end{array}$ \\
\hline A & 49 & 60.1 & 8,596 & 14,230 \\
B & 49 & 59.1 & 3,890 & 13,100 \\
C & 49 & 60.3 & 6,477 & 11,330 \\
D & 49 & 62.8 & 4,233 & 23,330 \\
\hline \hline
\end{tabular}

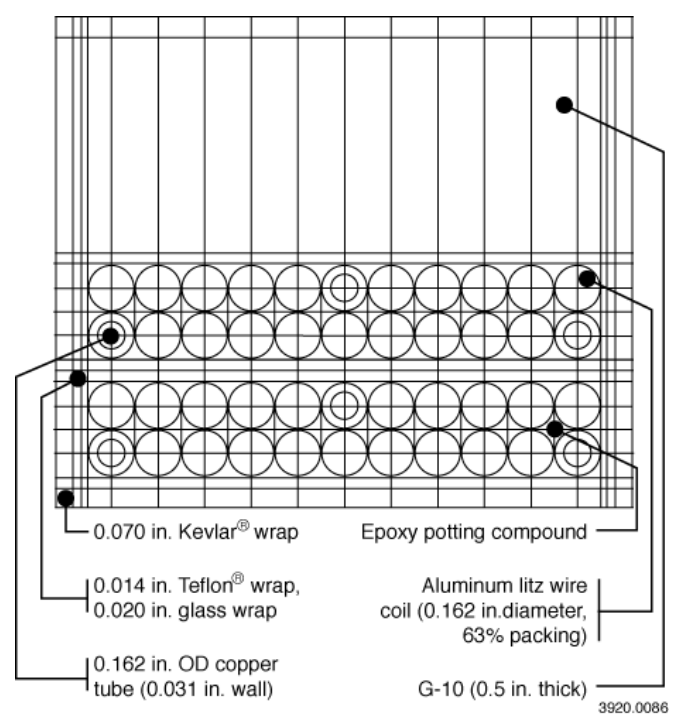

Figure 1. Stator armature coil cooling configuration A

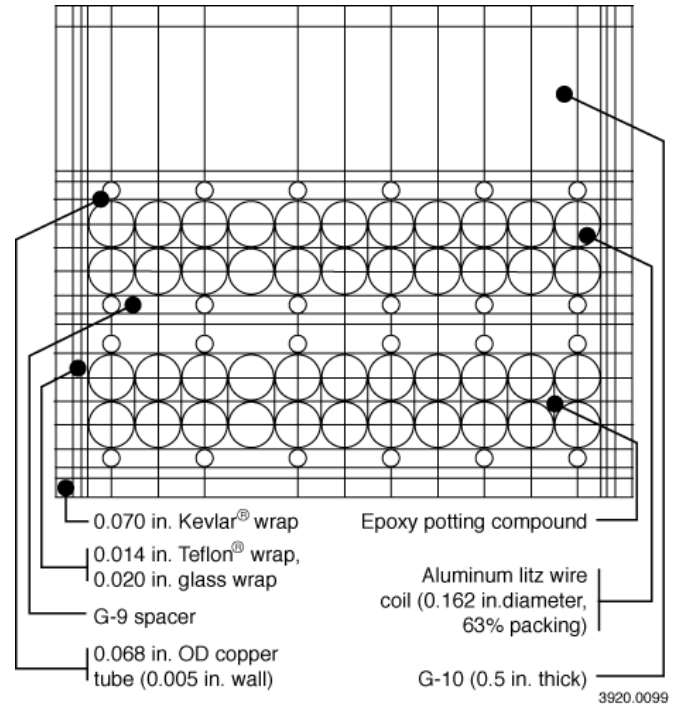

Figure 2. Stator armature coil cooling configuration B

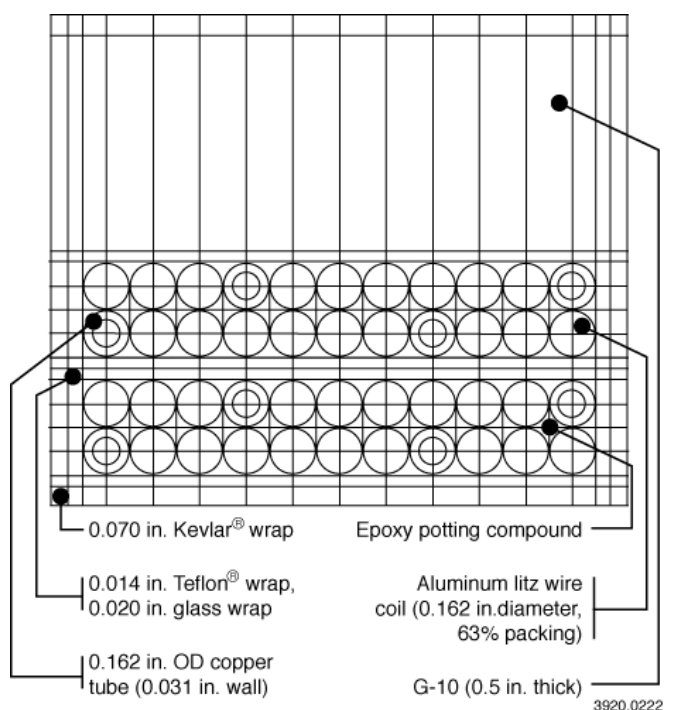

Figure 3. Stator armature coil cooling configuration C

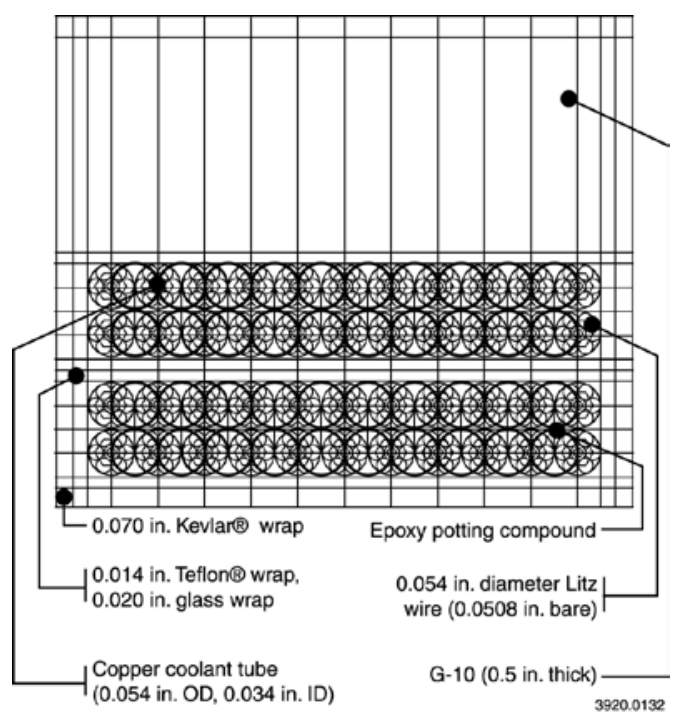

Figure 4. Stator armature coil cooling configuration D 


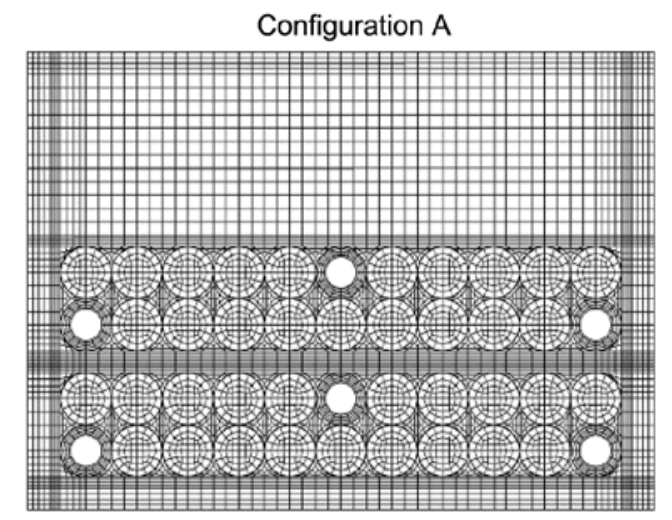

Configuration B

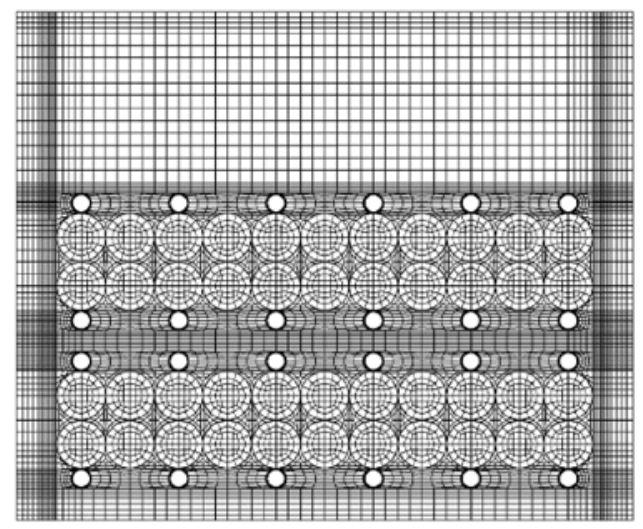

Configuration C

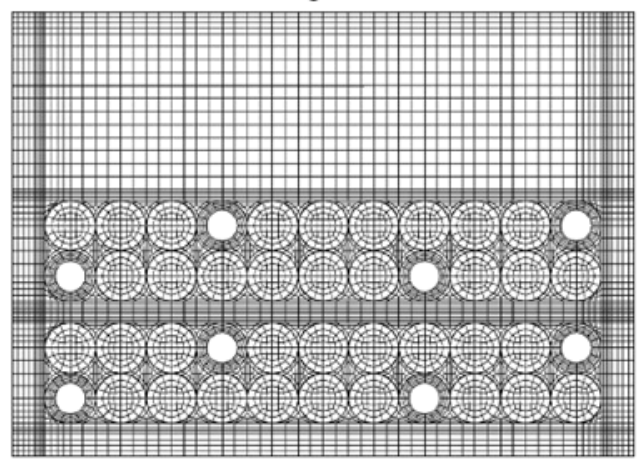

Configuration D

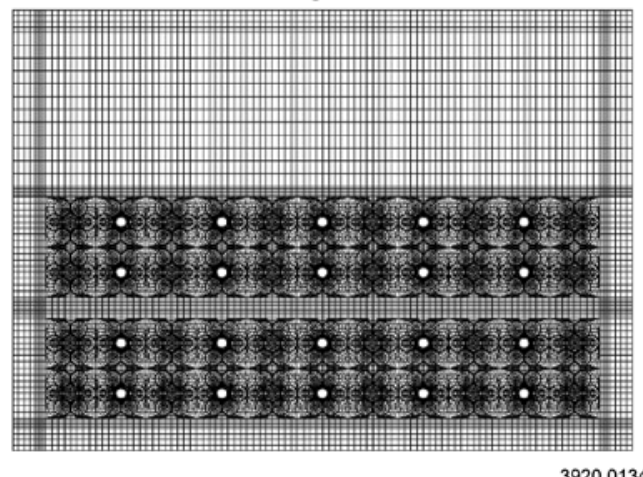

3920.0134

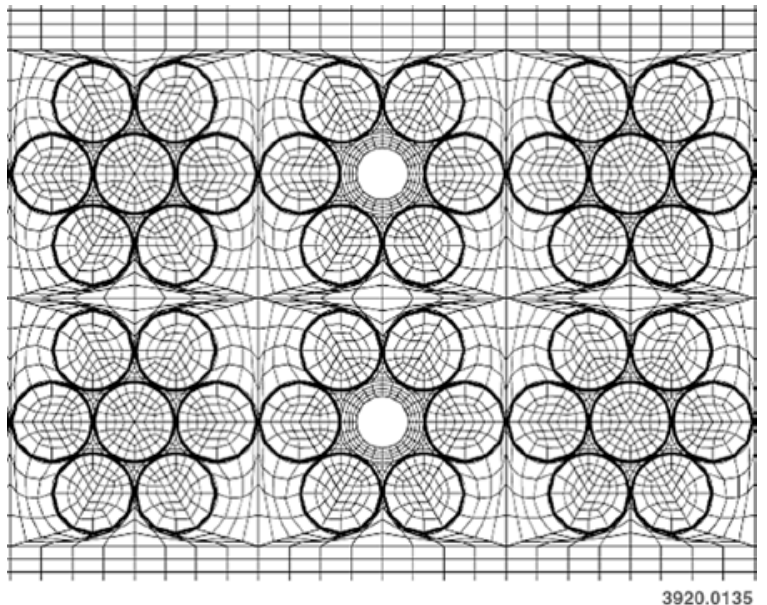

Figure 6. Locally enlarged planar finite element thermal model mesh of configuration D
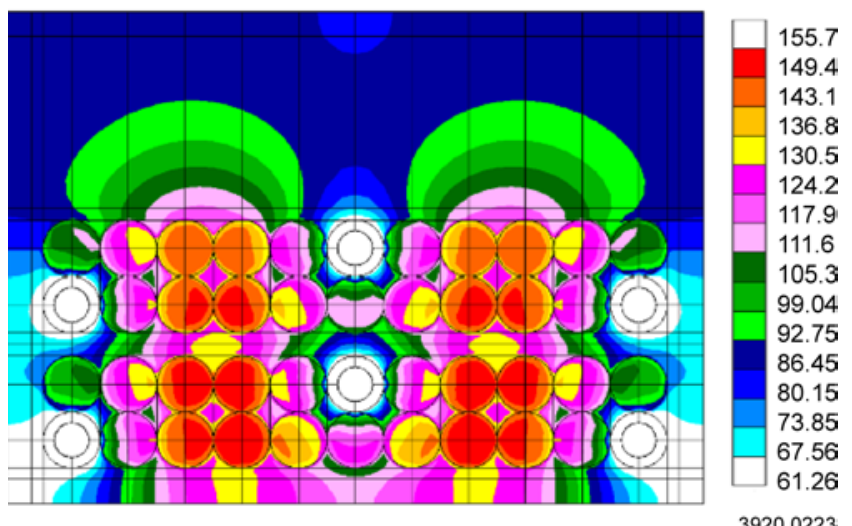

Figure 7. Stator temperature distribution $\left({ }^{\circ} \mathrm{C}\right)$ immediately after last shot (configuration A)

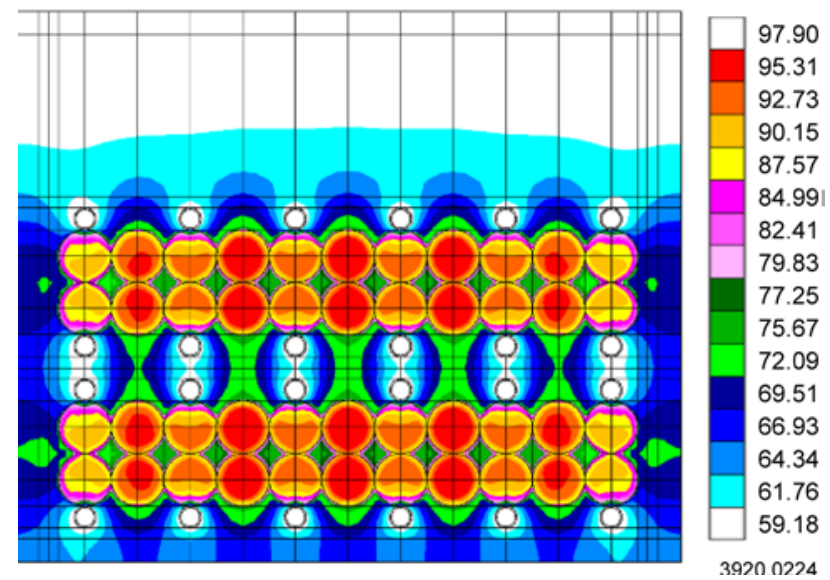

Figure 8. Stator temperature distribution $\left({ }^{\circ} \mathrm{C}\right)$ immediately after last shot (configuration B)

Figure 5. Planar finite element thermal model meshes (configurations A, $\mathrm{B}, \mathrm{C}$, and D) 

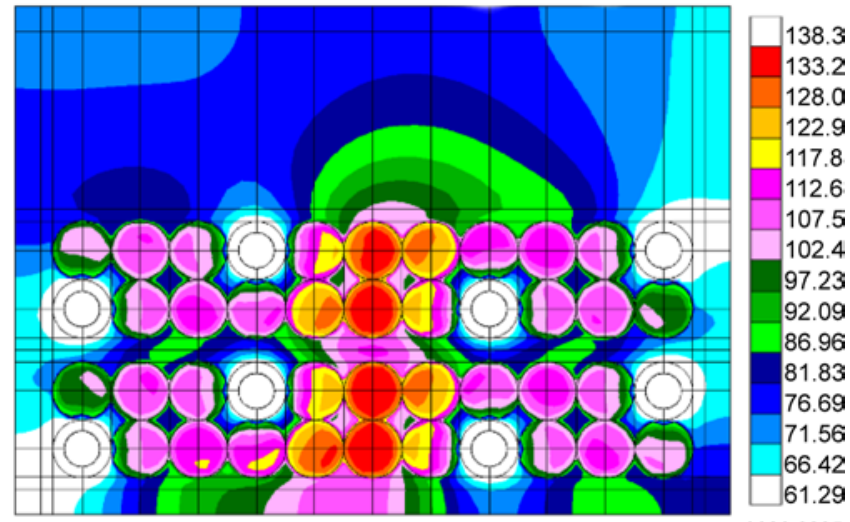

3920.0225

Figure 9. Stator temperature distribution $\left({ }^{\circ} \mathrm{C}\right)$ immediately after last shot (configuration C)
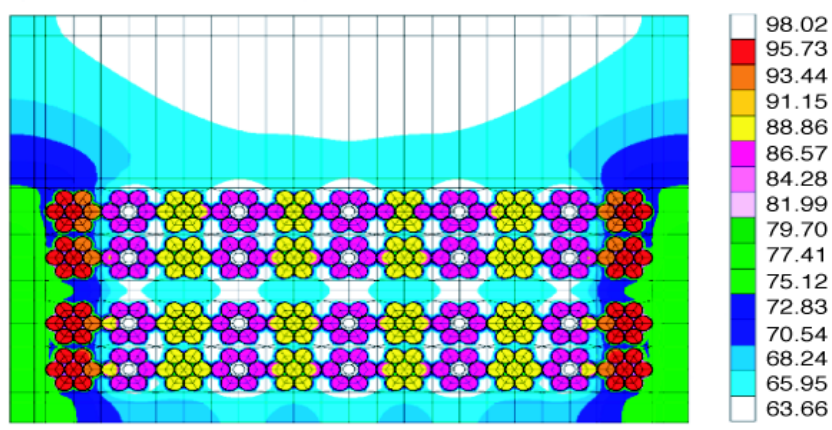

3920.0151

Figure 10 . Stator temperature distribution $\left({ }^{\circ} \mathrm{C}\right)$ immediately after last shot (configuration D)
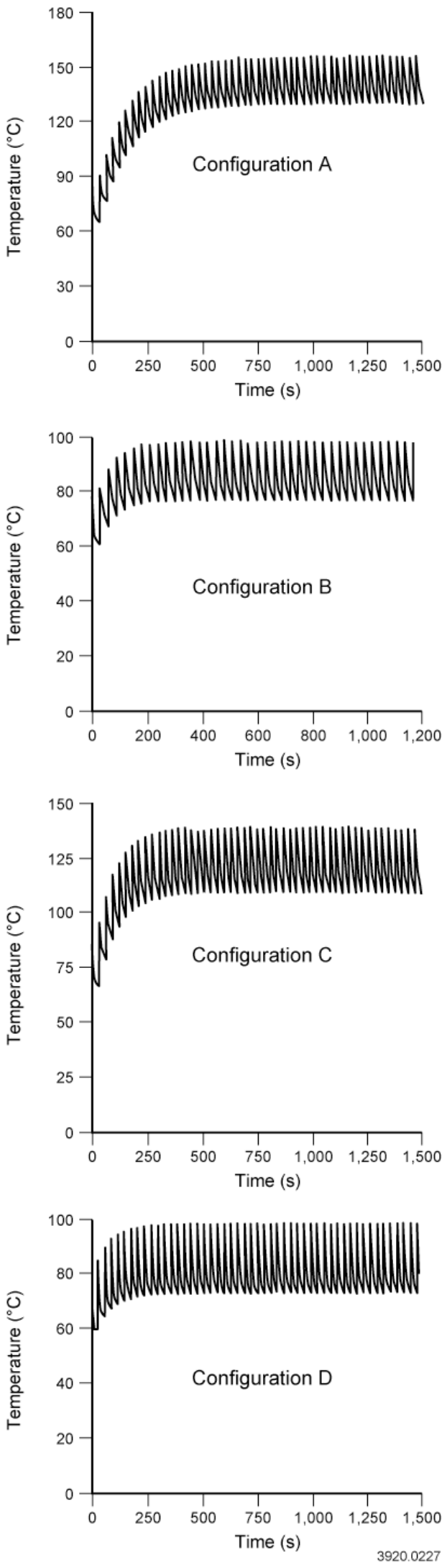

Figure 11. Transient maximum stator coil temperatures 